\title{
Genetic analysis of Paraoxonase (PON1) locus reveals an increased frequency of Arg192 allele in centenarians
}

\author{
Massimiliano Bonafè ${ }^{1,9}$, Francesca Marchegiani ${ }^{2,9}$, Maurizio Cardelli $^{2}$, Fabiola Olivieri ${ }^{2}$, \\ Luca Cavallone $^{2}$, Simona Giovagnetti ${ }^{2}$, Carlo Pieri ${ }^{2}$, Maurizio Marra ${ }^{2}$, Roberto Antonicelli ${ }^{2}$, \\ Leonarda Troiano ${ }^{3}$, Paola Gueresi ${ }^{4}$, Giovanni Passeri ${ }^{5}$, Maurizio Berardelli ${ }^{6,8}$, \\ Giuseppe Paolisso ${ }^{7}$, Michelangela Barbieri ${ }^{7}$, Silvia Tesei ${ }^{2}$, Rosmarie Lisa ${ }^{2}$, \\ Giovanna De Benedictis ${ }^{8}$ and Claudio Franceschi*,1,2
}

\begin{abstract}
${ }^{1}$ Department of Experimental Pathology, Bologna University, Bologna, Italy; ${ }^{2}$ Italian National Research Centers on Aging, Ancona, Italy; ${ }^{3}$ Department of Biomedical Sciences, University of Modena, Modena, Italy; ${ }^{4}$ Statistical Science, University of Bologna, Bologna, Italy; ${ }^{5}$ Institute of Internal Medicine and Medical Therapy, University of Parma, Parma, Italy; ${ }^{6}$ Department of Geriatrics and Internal Medicine, University of Magna Graecia, Catanzaro, Italy; ${ }^{7}$ Department of Geriatric Medicine and Metabolic Disease, II University of Naples, Naples, Italy;

${ }^{8}$ Department of Cell Biology, University of Calabria, Rende, Italy
\end{abstract}

Human Paraoxonase (PON1) is a High-Density Lipoprotein (HDL)-associated esterase that hydrolyses lipo-peroxides. PON1 has recently attracted attention as a protective factor against oxidative modification of LDL and may therefore play an important role in the prevention of the atherosclerotic process. Two polymorphisms have been extensively studied: a Leucine ( $\mathrm{L}$ allele) to Methionine ( $\mathrm{M}$ allele) substitution at codon 55, and a Glutamine (A allele) to Arginine (B allele) substitution at codon 192. We have examined these two aminoacidic changes in 579 people aged 20 to 65 years old, and 308 centenarians. We found that the percentage of carriers of the $B$ allele at codon 192 ( $B+$ individuals) is higher in centenarians than in controls ( 0.539 vs 0.447$)$, moreover we found that among the $B+$ individuals, the phenomenon was due to an increase of people carrying $\mathrm{M}$ alleles at codon 55 locus. In conclusion, we propose that genetic variability at PON1 locus affects survival at extreme advanced age.

European Journal of Human Genetics (2002) 10, 292 - 296. doi:10.1038/sj.ejhg.5200806

Keywords: polymorphism; human longevity; apolipoproteins; aging

\section{Introduction}

A great deal of data indicate that risk factors for the major causes of mortality in the elderly, (cardiovascular diseases, diabetes) are associated with alterations in anti-oxidant, inflammatory and lipidic profile. ${ }^{1-3}$ Particular importance has been attributed to the role of peroxidation of LDL in

${ }^{*}$ Correspondence: C Franceschi, Direzione Scientifica I.N.R.C.A., Villa Gusso, Via S. Margherita, 560124 Ancona, Italy. Tel: +39-071-8004764; Fax: +39-071-206791; E-mail: b.molecolare@inrca.it

${ }^{9}$ The first two authors contributed equally to this study

Received 12 December 2001; revised 8 March 2002; accepted 20 March 2002 atherogenesis and to the capability of lipoprotein-associated proteins of modulating local inflammatory response. ${ }^{4}$

Serum Paraoxonase 1 (PON1) has been claimed to play a central role in the scenario. The enzyme is a High Density Lipoprotein (HDL)-bound Arylesterase which hydrolises lipoperoxides and it is therefore responsible for the protective effects of HDL on peroxidation of Low Density Lipoproteins (LDL). ${ }^{5}$ Indeed, oxydised LDL are capable of stimulating the production of foam cells, are cytotoxic towards arterial wall cells, and induce macrophagic cytokines, resulting in highly proinflammatory and proatherogenic. ${ }^{6}$ The inter-individual variability of PON1 serum activity has been thought to modulate the risk to develop atherogenesis. In fact, the 
variability of the PON1 gene at codons 192 (Gln/Arg=A/B alleles) and 55 (Leu/Meth=L/M alleles) has been associated with enzymatic activity and concentration. ${ }^{7,8}$ Consistently, a large number of studies suggested an association between cardiovascular diseases and the $\operatorname{Arg}_{192}$ variant. ${ }^{9}$ Even Leu $_{55}$ has been associated with cardiovascular disease susceptibility. ${ }^{9}$ Recently, the role of $\operatorname{Arg}_{192}$ allele on CHD (cardiovascular heart disease) risk in the Italian population has been questioned $^{10}$ and recent data indicate that PON1 genotype affects the vasculature responsiveness to triglycerids. ${ }^{11}$ Interestingly, when the impact of $\mathrm{A} / \mathrm{B}$ and $\mathrm{L} / \mathrm{M}$ alleles of PON1 on mortality of individuals aged over 85 years of age was analysed, no significant effect has been found, leading to hypothesise that PON1 variants have not a major effect on the risk of fatal cardiovascular disease at the population level. $^{12}$

In this study we wanted to test the hypothesis that PON1 genotypes affect long term survival, i.e. whether allele, genotype and combined genotypes frequency distributions of centenarians are different from those found in young individuals.

\section{Materials and methods Subjects}

A sample of 579 Italian unrelated young individuals (347 males and 232 females, median age $=40.5$ years) ranging from 20 to 65 years of age and a sample of 308 Italian unrelated centenarians (241 females and 67 males) were analysed. The samples were recruited in both Northern Italy (368 young subjects and 216 centenarians) and Southern Italy (211 young subjects and 92 centenarians). Control subjects were apparently healthy at the time of blood collection judging from clinical examination and recent clinical history. All the subjects gave their informed consent.

\section{Genotyping}

DNA was extracted from blood lymphocytes by the saltingout method. ${ }^{13}$ Polymerase chain reactions were performed using primer sequences derived from published data and specific for the amplification of regions surrounding codon 192 and codon 55 sites. ${ }^{14}$ The amplification reaction for codon 192 locus was performed on a Perkin-Elmer Cetus 9700 thermal cycler with initial denaturation at $94^{\circ} \mathrm{C}$ for $4 \mathrm{~min}$, followed by 40 cycles, each one comprised of denaturation at $93^{\circ} \mathrm{C}$ for $1 \mathrm{~min}$, annealing at $64^{\circ} \mathrm{C}$ for $40 \mathrm{~s}$ and extension at $72^{\circ} \mathrm{C}$ for $1 \mathrm{~min}$, with a final extension time of $10 \mathrm{~min}$ at $72^{\circ} \mathrm{C}$. The PCR products were digested with AlwI (New England Biolabs) for $4 \mathrm{~h}$ at $37^{\circ} \mathrm{C}$, and the samples were electrophoresed in 2\% agarose gels. Amplification of the codon 55 polymorphism was performed on a Perkin-Elmer Cetus 9700 thermal cycler with initial denaturation at $96^{\circ} \mathrm{C}$ for $3 \mathrm{~min}$, followed by 35 cycles, each one comprised of denaturation at $95^{\circ} \mathrm{C}$ for $1 \mathrm{~min}$, annealing at $56^{\circ} \mathrm{C}$ for $1 \mathrm{~min}$ and extension at $72^{\circ} \mathrm{C}$ for $1 \mathrm{~min}$, with a final extension time of 5 min at $72^{\circ} \mathrm{C}$. The PCR products were digested with NlaIII (New England Biolabs) for $4 \mathrm{~h}$ at $37^{\circ} \mathrm{C}$, and the samples were electrophoresed in $2 \%$ agarose gels. Some genotypes at both loci were confirmed by direct sequencing of amplified DNA fragments with the automatic sequencer (ABI PRISM 310, Perkin Elmer Biosystem).

\section{Statistical analysis}

Allelic, genotypic and combined genotypes frequency distributions were compared by Monte Carlo $\chi^{2}$. Sex-specific age-related differences were assessed by Mantel-Haenszel test, implemented with SPSS package (SPSS, Chicago, IL, USA). HWE (Hardy-Weinberg Equilibrium) was checked by Monte Carlo Markov Chain. ${ }^{15}$ Estimation of maximum-likelihood multi-locus haplotype frequencies was calculated using an EM (Expectation Maximization) algorithm, implemented with Arlequin package. ${ }^{16}$ Standard Deviations were calculated by bootstrap (1000 replications). Difference in haplotype frequency distribution was assessed by Fisher exact test.

\section{Results}

PON1 192 alleles and genotypes in young people and centenarians

No significant difference was present between Northern and Southern Italians either in centenarians or in controls (data in http://biologia.unical.it/labs/genetica.html). Table 1 reports genotypes and alleles of the PON1 polymorphism at codon 192 in the whole Italian sample. In both the ageclasses the observed genotypes were in agreement with those expected at Hardy-Weinberg Equilibrium $(P>0.05)$. Significant differences between young people and centenarians were evident when allele and genotype frequency distributions were compared $\left(\chi^{2}=5.429, \mathrm{df}=1, P=0.020\right.$ for allele frequency, and $\chi^{2}=6.798, \mathrm{df}=2, P=0.034$ for genotype frequency). In particular, the proportion of $\mathrm{B}+$ subjects $(\mathrm{AB}+\mathrm{BB}$ individuals) was increased in centenarians in comparison to young people $\left(\chi^{2}=6.765, \mathrm{df}=1, P=0.011\right)$. The role of gender as a confounding variable was tested by $\mathrm{MH}$ test, and no significant result was found (data not shown).

\section{PON1 55 alleles and genotypes in young people and centenarians}

Again no geographic difference was observed either in centenarians or in young control subjects for PON1 codon 55 variants (data in http://biologia.unical.it/labs/genetica.html). Table 2 shows genotypes and alleles in the whole Italian sample. In both centenarians and young people the observed genotypes were in agreement with those expected at Hardy-Weinberg Equilibrium $(P>0.05)$. Unlike what has been observed at codon 192, allele and genotype frequency distributions were not statistically different between young people and centenarians. Moreover, the M+ subjects (LM plus MM individuals) were present at the same proportion in the two age-classes (0.598 vs 0.607, respectively). 
Table 1 Genotype and allele frequency distributions at PON1 192 locus

\begin{tabular}{|c|c|c|}
\hline & $\begin{array}{l}\text { Young subjects } \\
(\mathrm{n}=579) \mathrm{n}(\% \pm \text { s.e. })\end{array}$ & $\begin{array}{l}\text { Centenarians } \\
(\mathrm{n}=308) \text { n }(\% \pm \text { s.e. })\end{array}$ \\
\hline Genotypes $^{\mathrm{a}}$ & Observed Genotypes $^{a}$ & Observed Genotypes ${ }^{\mathrm{a}}$ \\
\hline AA subjects & $320(0.553 \pm 0.021)$ & $142(0.461 \pm 0.028)$ \\
\hline$A B$ subjects & $212(0.366 \pm 0.020)$ & $137(0.445 \pm 0.028)$ \\
\hline BB subjects & $47(0.081 \pm 0.011)$ & $29(0.094 \pm 0.017)$ \\
\hline $\mathrm{B}+$ subjects $^{\mathrm{b}}$ & $259(0.447 \pm 0.021)$ & $166(0.539 \pm 0.028)$ \\
\hline \multicolumn{3}{|l|}{ Alleles ${ }^{\mathrm{c}}$} \\
\hline$A$ allele & $852(0.735 \pm 0.013)$ & $421(0.683 \pm 0.019)$ \\
\hline $\mathrm{B}$ allele & $306(0.265 \pm 0.013)$ & $195(0.317 \pm 0.019)$ \\
\hline
\end{tabular}

${ }^{\mathrm{a}} \chi^{2}=6.798, \mathrm{df}=2, \quad P=0.034 ;{ }^{\mathrm{b}} \chi^{2}=6.765, \mathrm{df}=1, P=0.011 ;{ }^{c} \chi^{2}=5.429$, $\mathrm{df}=1, P=0.020$.

Table 2 Genotype and allele frequency distributions at PON1 55 locus

\begin{tabular}{lll}
\hline & $\begin{array}{l}\text { Young subjects } \\
(\mathrm{n}=579) \mathrm{n}(\% \pm \text { s.e. })\end{array}$ & $\begin{array}{l}\text { Centenarians } \\
(\mathrm{n}=308) \mathrm{n}(\% \pm \text { s.e. })\end{array}$ \\
\hline Genotypes $^{\mathrm{a}}$ & Observed Genotypes $^{\mathrm{a}}$ & Observed Genotypes $^{\mathrm{a}}$ \\
LL subjects & $233(0.402 \pm 0.020)$ & $121(0.393 \pm 0.028)$ \\
LM subjects & $262(0.453 \pm 0.021)$ & $155(0.503 \pm 0.028)$ \\
MM subjects & $84(0.145 \pm 0.015)$ & $32(0.104 \pm 0.017)$ \\
$\begin{array}{l}\text { M+ subjects } \\
\text { Alleles }\end{array}$ & $346(0.598 \pm 0.020)$ & $187(0.607 \pm 0.028)$ \\
$\quad$ L allele & $728(0.629 \pm 0.014)$ & $397(0.644 \pm 0.019)$ \\
$\quad M$ allele & $430(0.371 \pm 0.014)$ & $219(0.356 \pm 0.019)$ \\
\hline
\end{tabular}

${ }^{a} \chi^{2}=3.754, d f=2, P=0.155 ;{ }^{b} \chi^{2}=0.077, d f=1, P=0.829 ;{ }^{c} \chi^{2}=0.433$, $\mathrm{df}=1, P=0.535$.
Combined analysis of PON1 192/55 loci in young people and centenarians

Since the haplotype estimation from population data is found on the assumption of homogeneity of the population, and is therefore very sensitive to possible stratification, haplotype analysis in young people and centenarians was carried out first in Northern and Southern Italians separately (data in http://biologia.unical.it/labs/genetica.html). As no significant geographic difference was observed either in young people or in centenarians, the following analyses were carried out in the whole Italian sample. The results are shown in Table 3. A significant difference in estimated haplotype frequency distributions was found between young people and centenarians (Fisher Exact Test, $P=0.012$ ). The difference was predominately due to an increase of $\underline{B M}$ haplotype in centenarians $(1.4 \%)$ in comparison to that found in young people $(0.3 \%)$.

We therefore thought it worthwhile to investigate the combination of genotypes at codons 192 and 55 (Table 4), and we found that their distributions were significantly different between young subjects and centenarians $\left(\chi^{2}=11.525\right.$, d.f.=3, $\left.P=0.010\right)$. In particular, we found that $\mathrm{B}+$ subjects $\left(\operatorname{Arg}_{192}+\right)$ could be sub-grouped on the basis of the genotype at codon 55 as $\mathrm{M}+$ and $\mathrm{M}-$, and that only $\mathrm{B}+\mathrm{M}+$ individuals (AB.LM, AB.MM, BB.LM) were increased in centenarians $(0.173$ in young people $v s 0.263$ in centenarians), whilst the proportion of $\mathrm{B}+\mathrm{M}$ - individuals

Table 3 PON1 codon192/codon 55 haplotypes frequency distribution

\begin{tabular}{|c|c|c|c|c|c|c|}
\hline Haplotype $^{\mathrm{a}}$ & Mle & $\begin{array}{c}\text { Young subjects } \\
\text { (1158 chromosomes) } \\
\text { Exp }\end{array}$ & Haplotyp & $n c y \pm s . d$ & $\begin{array}{l}\text { Centenarians } \\
\text { (616 chromosomes) } \\
\text { Exp }\end{array}$ & $D^{c}$ \\
\hline
\end{tabular}

Table 4 Genotype combinations at PON1 codon 192 and codon 55

\begin{tabular}{|c|c|c|}
\hline & $\begin{array}{l}\text { Young subjects } \\
(\mathrm{n}=579) \mathrm{n}(\% \pm \text { s.e. })\end{array}$ & $\begin{array}{l}\text { Centenarians } \\
(\mathrm{n}=308) \mathrm{n}(\% \pm \text { s.e. })\end{array}$ \\
\hline Genotype & Observed genotype & Observed genotype \\
\hline Combinations $^{\mathrm{a}}$ & combinations & combinations \\
\hline $\begin{array}{l}\text { B+M+subjects } \\
(A B \cdot L M+A B \cdot M M+B B \cdot L M)\end{array}$ & $100(0.173 \pm 0.016)$ & $81(0.263 \pm 0.025)$ \\
\hline $\begin{array}{l}\mathrm{B}+\mathrm{M}-\text { subjects } \\
(\mathrm{AB} \cdot \mathrm{LL}+\mathrm{BB} \cdot \mathrm{LL})\end{array}$ & $159(0.275 \pm 0.018)$ & $85(0.276 \pm 0.025)$ \\
\hline $\begin{array}{l}\text { B-M+subjects } \\
\text { (AA.LM+AA.MM) }\end{array}$ & $246(0.424 \pm 0.021)$ & $106(0.344 \pm 0.027)$ \\
\hline $\begin{array}{l}\mathrm{B}-\mathrm{M}-\text { subjects } \\
\text { (AA.LL) }\end{array}$ & $74(0.128 \pm 0.014)$ & $36(0.117 \pm 0.018)$ \\
\hline
\end{tabular}

${ }^{\mathrm{a}} \chi^{2}=11.525, \mathrm{df}=3, P=0.010$. 
(AB.LL+BB.LL) did not change appreciably (0.275 in controls vs 0.276 in centenarians).

\section{Discussion}

Taking into account the physiological role of the enzyme Paraoxonase 1 , which may play a central role in rate and quality of ageing, ${ }^{17}$ we investigated the possible association of PON1 genetic variability with longevity, i.e. the capacity of reaching the extreme limits of human life span escaping major age-related diseases.

When the two variants $A / B_{192}$ and $L / M_{55}$ were analysed separately (Tables 1 and 2), we found that PON1 variability at 192 codon was able to discriminate between young people and centenarians. In particular, the frequency of B allele, and consequently of $\mathrm{B}+$ individuals, increased from young people to centenarians, thus indicating that this allele decreases mortality in carriers. When the two variants $\mathrm{A} / \mathrm{B}_{192}$ and $\mathrm{L} /$ $\mathrm{M}_{55}$ were analysed together (Table 4 ) only $\mathrm{B}+\mathrm{M}+$ individuals increased from young people to centenarians, thus indicating that this genotype combination decreases mortality in carriers.

It should be noted that, given the large sample size, the observed gene/longevity association is not highly significant. This finding implies that the effect of PON1 variability on the overall population mortality is rather slight, and this finding is in line with the results obtained in several gene/longevity association studies. ${ }^{18}$ Moreover, the $\mathrm{AB}_{192}$ heterozygous genotype appears to contribute rather largely to the observed association (Table 1). A recently developed mathematical model explains the variation of heterozygosity in an ageing cohort in terms of differential survival as affected by the biological role of the gene. ${ }^{19}$ According to the model, centenarians are expected to show increasing heterozygosity with respect to young subjects for stress-responder genes driving the individual adaptive capacity. Data in Table 1 suggest that PON1 is one of the genes affecting such adaptive capability, and therefore one of the genes affecting rate and quality of ageing.

The finding that the $\mathrm{B}_{192}$ allele is more frequent in centenarians than in young people seems to be contradictory with literature data reporting the role of this allele as risk factor in artery and coronary diseases, carotid stenosis, cardiovascular diseases, vascular dementia. ${ }^{10,20-22}$ However, the data are still conflicting. What is more, these discrepancies may be related to different criteria of recruitment, different average age of the sample groups, different experimental design (for example the fact that in some studies $A / B_{192}$ variants have been examined without taking into account other variants of PON1 gene, such as $\mathrm{L} / \mathrm{M}_{55}$ variants). Probably, the population genetic history as well as the presence of other risk factor for CVD play a key role in determining association between $\mathrm{A} / \mathrm{B}_{192}$ alleles and CVD. It is of interest that studies carried out in the Mediterranean area do not support the existence of a significant association between PON1 A/B 192 genetic polymorphism and CVD. ${ }^{10,21-}$ ${ }^{23}$ On the other hand, carriers of B allele (B+ subjects) seem to be protected when other known risk factors for CVD are present, such as smoking, ${ }^{24}$ familiar hypercolesterolemia, ${ }^{25}$ low HDL-cholesterol levels. ${ }^{26}$ Anyway, even if the role of the $\mathrm{B}$ allele as risk factor were ascertained, the presence of a genetic risk factor in the gene pool of centenarians is not unusual. The above cited mathematical model ${ }^{19}$ is able to explain such 'paradoxes in centenarians' taking into account the biological and physiological role of risk alleles in survival, and the heterogeneity of the today population of centenarians. In any case, an increasing number of data indicate that long life expectancy is compatible with genetic risk factors, ${ }^{27-30}$ when the individual genetic background is able to cope with stress and consequent age-related accumulation of somatic damage. ${ }^{31}$

PON1 activity is involved in the protection of LDL against oxidative/proinflammatory modifications which play a central role in the pathogenesis of arteriosclerosis and cardiovascular diseases. ${ }^{6}$ As the increase of $\mathrm{B}+\mathrm{M}+$ individuals among centenarians suggests a genetically determined Paraoxonase activity advantageous for longevity, it could be hypothesised that such individuals are provided with an elicited capacity to counteract the deleterious effects of the accumulation of pro-inflammatory molecules and the increase of the proinflammatory status which accompany human aging. ${ }^{31}$ Functional studies of correlation between PON1 genotype and PON1 activity in cells from centenarians may clarify this point.

\section{Acknowledgements}

This work was financed by Ministry of Health 'Progetto finalizzato 1997: la prevenzione della morbilità per malattie croniche nell'età avanzata. Il modello dei centenari' and 'Progetto finalizzato 1998: interazioni tra fattori di rischio cardiovascolari e fattori genetici dell'aterosclerosi e della trombosi: un approccio integrato geneticofunzionale in casistiche selezionate' and by COFIN 2000-2002 Genetics Determinants of Human Longevity.

\section{References}

1 Diaz MN, Frei B, Vita JA, Keaney Jr JF: Antioxidants and atherosclerotic heart disease. N Engl J Med 1997; 337: 408 - 416.

2 Ridker PM: Inflammation, atherosclerosis, and cardiovascular risk: an epidemiologic view. Blood Coagul Fibrinolysis 1999; 10: S9-S12.

3 Cheng S, Grow MA, Pallaud C et al: A multilocus genotyping assay for candidate markers of cardiovascular disease risk. Genome Research 1999; 9: 936-949.

4 Navab M, Berliner JA, Subbanagounder G et al: HDL and the inflammatory response induced by LDL-derived oxidized phospholipids. Arterioscler Thromb Vasc Biol 2001; 21: 481 - 488.

5 Watson AD, Berliner JA, Hama SY et al: Protective effect of high density lipoprotein associated paraoxonase: inhibition of the biological activity of minimally oxidized low density lipoprotein. J Clin Invest 1995; 96: 2882-2891.

6 Ross R: Atherosclerosis - an inflammatory disease. The New Eng J Med 1999; 340: 115-126. 
20 Hegele RA: Paraoxonase genes and disease. Ann Med 1999; 31: $217-224$

7 Adkins S, Gan KN, Mody M, La Du BN: Molecular basis for the polymorphic forms of human serum paraoxonase/arylesterase: glutamine or arginine at position 191, for the respective A or B allozymes. Am J Hum Genet 1993; 52: 598-608.

8 Blatter-Garin MC, James RW, Dussoix P et al: Paraoxonase polymorphism Met-Leu54 is associated with modified serum concentrations of the enzyme. J Clin Invest 1997; 99: 62-66.

9 Durrington PN, Mackness B, Mackness MI: Paraoxonase and atherosclerosis. Arterioscler Thromb Vasc Biol 2001; 21: 473-480.

10 Ombres D, Pannitteri G, Montali A et al: The gln-Arg192 polymorphism of human paraoxonase gene is not associated with coronary artery disease in Italian patients. Arterioscler Thromb Vasc Biol 1998; 18: 1611-1616.

11 Paolisso G, Manzella D, Tagliamonte MR et al: The BBparaoxonase genotype is associated with impaired brachial reactivity after acute hypertriglyceridemia in healthy subjects. $J$ Clin Endocrinol Metab 2001; 86: 1078-1082.

12 Heijmans BT, Westendorp RG, Lagaay AM, Knook DL, Kluft C, Slagboom PE: Common paraoxonase gene variants, mortality risk and fatal cardiovascular events in elderly subjects. Atherosclerosis 2000; 149: $91-97$.

13 Miller SA, Dykes DD, Polesky HF: A simple salting-out procedure for extracting DNA from human nucleated cells. Nucleic Acids Res 1989; 16: 1215

14 Humbert R, Adler DA, Disteche CM, Hassett C, Omiecinski CJ, Furlong CE: The molecular basis of the human serum paraoxonase activity polymorphism. Nat Genet 1993; 3: 73-76.

15 Guo SW, Thompson EA: A Monte Carlo method for combined segregation and linkage analysis. Am J Hum Genet 1992; 51: $1111-1126$

16 Schneider S, Roessli D, Excoffier L: Arlequin ver 2000: a software for population genetics data analysis. Genetics and Biometry Laboratory, Switzerland: University of Geneva.

17 Franceschi C, Bonafe M, Valensin S et al: Inflamm-aging. An evolutionary perspective on immunosenescence. Ann N Y Acad Sci 2000; 908: 244-254.

18 De Benedictis G, Qihua Tan, Jeune B et al: Recent advances in human gene/longevity association studies. Mech Ageing Dev 2001; 122: 909 - 920 .

19 Yashin AI, Ukraintseva SV, De Benedictis G et al: Have the oldest old adults ever been frail in the past? A hypothesis that explains modern trends in survival. J Gerontol A Biol Sci 2001; 56: B432442.
21 Dessi M, Gnasso A, Motti C et al: Influence of the human paraoxonase polymorphism (PON1 192) on the carotid-wall thickening in a healthy population. Coron Artery Dis 1999; 10: $595-599$.

22 Zuliani G, Ble' A, Zanca R et al: Genetic polymorphisms in older subjects with vascular or Alzheimer's dementia. Acta Neurol Scand 2001; 103: 304-308.

23 Herrmann SM, Blanc H, Poirier O et al: The Gln/Arg polymorphism of human paraoxonase (PON 192) is not related to myocardial infarction in the ECTIM Study. Atherosclerosis 1996; 126: $299-303$

24 Senti M, Aubo C, Tomas M: Differential effects of smoking on myocardial infarction risk according to the Gln/Arg 192 variants of the human paraoxonase gene. Metabolism 2000; 49: $557-559$.

25 Leus FR, Wittekoek ME, Prins J, Kastelein JJ, Voorbij HA: Paraoxonase gene polymorphisms are associated with carotid arterial wall thickness in subjects with familial hypercholesterolemia. Atherosclerosis 2000; 149: 371 - 377.

26 Senti M, Tomas M, Marrugat J, Elosua R: REGICOR Investigators. Paraoxonase1-192 polymorphism modulates the nonfatal myocardial infarction risk associated with decreased HDLs. Arterioscler Thromb Vasc Biol 2001; 21: 415-420.

27 Mannucci PM, Mari D, Merati G et al: Gene polymorphisms predicting high plasma levels of coagulation and fibrinolysis proteins. A study in centenarians. Arterioscler Thromb Vasc Biol 1997; 17: $755-759$.

28 Robine JM, Forette C, Franceschi C: 1999. The paradoxes of longevity. Allard M (ed): New York: Springer-Verlag.

29 Rose G, Passarino G, Carrieri G et al: Paradoxes in longevity: sequence analysis of mtDNA haplogroup J in centenarians. Eur J Hum Genet 9: 701 - 707.

30 Bonafè M, Barbi C, Olivieri F et al: 2002 An allele of HRAS1 3 variable number of tandem repeats is a frailty allele: implication for an evolutionary conserved pathway involved in longevity. Gene 286:121-126.

31 Franceschi $\mathrm{C}$, Valensin S, Bonafe $\mathrm{M}$ et al: The network and the remodeling theories of aging: historical background and new perspectives. Exp Gerontol 2000; 35: 879-896. 